\title{
Computer-assisted cognitive behavior therapy for obsessive-compulsive disorder: a randomized trial on the impact of lay vs. professional coaching
}

\author{
Kenneth A Kobak ${ }^{1 *}$, Revere Greist ${ }^{2}$, David M Jacobi ${ }^{3}$, Hollie Levy-Mack ${ }^{4}$ and John H Greist ${ }^{5}$
}

\begin{abstract}
Background: The purpose of the study was to examine the impact of computerized cognitive behavior therapy (CBT) self-help treatment for obsessive-compulsive disorder (OCD) (BT Steps) both alone and when supported by coaching from either a lay non-therapist coach or an experienced CBT therapist.

Methods: Eighty-seven subjects with clinically significant OCD were recruited through newspaper ads and randomly assigned to receive 12 weeks of treatment with either BT Steps alone $(n=28)$, BT Steps with non-therapist coaching $(n=28)$, or BT Steps with CBT therapist coaching $(n=31)$. Subjects worked on BT Steps at their own pace. Subjects receiving BT Steps alone received a welcome call from the project manager. Subjects randomized to either of the coaching arms received regularly scheduled weekly phone calls for coaching, encouragement, and support. No formal therapy was provided by the coaches; thus, both lay and CBT coaches completed the same tasks.

Results: All three treatment arms showed a significant reduction in Yale-Brown Obsessive Compulsive Scale (YBOCS) scores, with mean (SD) changes of 6.5 (5.7), 7.1 (6.1), and 6.5 (6.1) for the no coaching, lay coaching, and therapist coaching arms, respectively (all $p^{\prime} s<.001$ ). These represent effect sizes of 1.16, 1.41, and 1.12, respectively. No significant differences were found between treatment arms on YBOCS change scores, $F(2)=0.10, p=.904$, or number of exposures sessions done $(F(2)=0.033, p=.967)$. When asked which method of therapy (computer vs. clinician) they preferred, 48\% said computer, 33\% said face-to-face therapy, and 19\% had no preference.
\end{abstract}

Conclusions: Results support the use of online self-help for the treatment of moderate OCD. The addition of coaching by either a lay coach or a CBT therapist coach did not significantly improve outcomes.

Keywords: Computerized self-instruction program, Cognitive behavior therapy, Obsessive compulsive disorder

\section{Introduction}

Obsessive-compulsive disorder (OCD), once thought to be a rare condition refractory to treatment, is now known to be surprisingly common. The lifetime prevalence in the US for adults is $2.6 \%$ [1] with a 1-year prevalence of $1 \%$ [2]. OCD is classified as a severe mental illness by the National Advisory Mental Health Council $[3,4]$ and can be incapacitating, ranking 11th among all medical diseases for disability [5]. Direct and indirect costs of OCD have been estimated to be $\$ 8.4$ billion [6]. Performing rituals may become a major life activity, severely interfering with one's job, marriage, or

\footnotetext{
* Correspondence: kkobak@telepsychology.net

'Center for Telepsychology, 7601 Ganser Way, Madison, WI 53719, USA

Full list of author information is available at the end of the article
}

other social relationships [7-9]. Comorbid depression is common, with increased levels of suicidal ideation and attempts [10]. OCD has been reclassified in the Diagnostic and Statistical Manual of Mental Disorders Fifth Edition [11] (DSM5) from an anxiety disorder to a new category of disorders, obsessive-compulsive and related disorders [11]. This was based in part on data from studies on symptom phenomenology, treatment response, familialty, genetics, neurocircuitry, and cognitive functioning (see Stein et al. [12] for a review). Brain imaging studies have found a unique pattern of neuronal activation not present in other anxiety disorders (i.e., baseline hyperactivity and hyper-response in the lateral orbitofrontal cortex, anterior cingulate cortex, and caudate). Unique deficits in cognitive functioning have also been found, involving 
difficulties with cognitive flexibility and response inhibition $[13,14]$. OCD is one of the first disorders to be reclassified based in part upon biomarker evidence, and thus in line with current trends in the classification of mental disorders as outlined by Research Diagnostic Criteria (RDoC) [15].

Cognitive behavior therapy (CBT) with exposure and ritual prevention (E \& RP) is recommended as a firstline treatment for OCD by clinical practice guidelines in both the US and abroad [16-18]. Several decades of research support both its efficacy and effectiveness [19-23]. It has effect sizes as large as pharmacological interventions [24], with lower relapse rates [25-27]. CBT is considered an empirically supported treatment (EST), i.e., a treatment shown to be efficacious in controlled research with a defined population [28]. There has been a growing emphasis on the need for ESTs from both legal, ethical, and economic perspectives [29-31], and professional and ethical guidelines now require therapists to integrate ESTs into their practice [30,31]. However, with this increased emphasis has come increased demand. As a result, the number of therapists trained in CBT falls far short of the demand [32,33]. The percentage of patients with OCD actually receiving CBT treatment ranges from $5 \%$ to $7 \%[34,35]$, in spite of the fact that persons with OCD have been found to prefer CBT (either alone or in combination with medication) over treatment with medication alone [36]. Sixty percent of OCD patients receive no treatment at all, and the gap between onset of symptoms and effective treatment averages 17 years [37].

New technologies may provide an opportunity to help solve this problem [38]. A growing body of research has found that computerized self-administered CBT (CCBT) is highly effective, achieving clinical improvements similar to those obtained with therapist-administered CBT [39-42]. A recent meta-analysis of randomized, controlled trials of CCBT for anxiety or depressive disorders found a substantial effect size for CCBT ( $g=0.77$, 95\% confidence interval (CI) 0.59-0.95) [41], with gains sustained up to 3 years after treatment [43]. Studies of CCBT for OCD have found it to be an effective treatment [44-48], with effect sizes similar to those found with therapist-administered CBT [44,47,49,50]. Gains were maintained at 3- and 4-month follow-up. CCBT can be offered at a reduced cost, cited by patients in one study as the main barrier to seeking treatment [51]. Patients can work at their own pace on their own schedule, and CCBT provides a treatment option for those who fail to seek treatment due to fears of social stigma [52-54]. A recent survey of OCD patients found that they considered CCBT an acceptable form of treatment, with the most common advantages reported being reduced time (67\%), no need for travel $(63 \%)$, reduced costs $(60 \%)$, and privacy/anonymity (56\%) [55]. Only 10\% reported preferring face-to- face treatment. Economic studies of CCBT for OCD have found it to be a cost-effective treatment compared to therapist-administered CBT [56,57].

As with any treatment, adherence is required for the treatment to exert its effect. Our previous work on CCBT for OCD found a clear dose-response relationship: patients who did more CBT homework sessions had greater decreases in symptoms [46]. Studies have found that "computer-assisted" programs (CCBT with limited human contact) fare better than fully "computerized" (no human contact) programs, the former being associated with higher treatment adherence and lower dropout rates [53]. Adding human 'coaching' to computer-administered CBT treatments has been found to enhance treatment compliance, patient satisfaction, and outcomes $[46,53,58,59]$. Human coaching appears to be effective in motivating patients to actually confront their fears using the exposure therapy techniques they learn in the self-help treatment programs and to complete their between session homework assignments. This 'hybrid' model of computerized self-help combined with human coaching has been endorsed and implemented by the United Kingdom National Health Servicethe first governmental regulatory body to recommend web-based self-help CBT treatment [60]. It utilizes a model with limited human contact with non-therapist coaches. However, the level of human support and whether coaching is done by a therapist or nontherapist have not been empirically examined [53]. Using trained non-therapist 'coaches' may be a costeffective means of improving outcomes. According to 'stepped care' models of treatment, matching the appropriate level of intervention, starting with the least restrictive and most effective, enhances treatment outcomes, controls healthcare costs, and helps allocate scarce mental health resources more effectively [61-64]. Recent studies of stepped care in OCD found equivalent treatment outcomes to standard clinical CBT but significantly lower treatment costs [65-67]. While CCBT fits nicely in the stepped care model, understanding the differences in treatment outcome associated with lay vs. therapist CCBT coaches will help inform the stepped care model. This goal of this study was to examine the impact of computerized self-help treatment for OCD alone and in combination with either a lay non-therapist coach or coaching provided by an experienced CBT therapist.

\section{Method}

\section{Subjects}

Eighty-seven subjects with a minimum Yale-Brown Obsessive-Compulsive Scale (YBOCS) [68] score of 16 and a maximum score of 32 were enrolled. This range includes clinically significant OCD but not highest severity. Subjects were recruited through newspaper ads 
and from referrals from community therapists from January 2012 through December 2013. Subjects were excluded if they had psychotic symptoms, significant comorbid depression (defined as score of 20 or greater on the computer-administered Hamilton Depression Rating Scale [69]), or if they were a serious suicide risk (as measured by a score of 3 or greater on ideation on the Columbia Suicidality Severity Rating Scale (C-SSRS) [70] or any suicidal behavior endorsed on the C-SSRS). Seventy-two percent of subjects had at least one comorbid psychiatric diagnosis as determined by the Structured Clinical Interviews for DSM-IV [71] (SCID) (substance abuse $=6$, eating disorders $=2$, major depression $=11$, dysthymia $=4$, depression not otherwise specified $=9$, panic disorder $=9$, generalized anxiety disorder $=9$, posttraumatic stress disorder $=4$, social phobia $=10$, bipolar disorder $=3$, attention-deficit/hyperactivity disorder $=6$ ).

The study was reviewed and approved by the Allendale Institutional Review Board, and all subjects signed informed consent statements approved by the board. Demographic data on the subjects are presented in Table 1. A significantly greater percentage of subjects in the therapist coaching arm had at least a 2-year college degree $\left(\chi^{2}(2)=\right.$ $6.42, p=.04)$. There were no other significant differences between patients in the treatment arms on any other demographic variables at baseline. Thirty-four subjects $(38.6 \%)$ were currently in treatment for OCD (medication alone $=13$, psychotherapy alone $=4$, combination medication and psychoherapy $=16$ ). Average duration of current treatment was 5.4 years. Of the 20 subjects receiving psychotherapy, 14 reported that their therapist uses some CBT techniques as part of their approach. There were no significant differences between groups on the percentage of patients receiving concurrent psychotherapy, $\left(\chi^{2}(2)=1.41, p=.49\right)$.

\section{Procedure}

Subjects were randomly assigned to receive 12 weeks of treatment in one of three treatment arms: BT Steps alone $(n=28)$, BT Steps with non-therapist coaching $(n=28)$, and BT Steps with CBT therapist coaching $(n=31)$. Subjects were randomized using a computergenerated randomization schedule. Subjects worked on the BT Steps program at their own pace. Subjects assigned to BT Steps without coaching received a welcome and orientation call from the project manager. Subjects randomized to either of the coaching arms received the welcome call plus regularly scheduled weekly phone calls for coaching, encouragement, and support. Calls focused on the user's progress in BT Steps, troubleshooting problems they were having with the program, and setting progress goals for the next coaching session. No formal therapy was provided by the coaches; thus, both lay and CBT coaches completed the same tasks. Two CBT coaches (DMJ and HLM) and one lay coach (RG) were used in the study. The lay coach was supervised by the CBT therapist and could consult with them as needed.

\section{Overview of BT Steps content}

Step 1 ('Learning About BT Steps') provides an overview of the program and explains the principles of treatment (exposure and response prevention (ERP)). In Step 2 (Identifying Major Rituals and Their Costs), ERP is explained in more detail. Subjects identify their main rituals and obsessions and how much these affect their lives in terms of time and money. In Step 3 (Identifying Triggers and Setting Goals), subjects review a list of 162 stimulus triggers to identify those that trigger their own rituals and obsessions and rate the discomfort each trigger causes. Step 4 (Co-therapy with a Relative or Friend) helps subjects decide whether to involve a relative or friend as an exposure co-therapist and educates the cotherapist on how to best facilitate treatment. In Step 5 (First Exposure and Ritual Prevention [E \& RP]), subjects choose their first trigger and develop a detailed goal for first exposure. Coping tactics are reviewed to enable them to complete exposure and ritual prevention successfully. Step 6 (Fine Tuning) reviews results from their exposure session and advises them how to improve subsequent sessions. Subjects can return to Step 6 as needed. Patients document results in an online diary

Table 1 Demographic data by treatment arm

\begin{tabular}{|c|c|c|c|c|c|c|}
\hline & College degree $^{a}$ & Percent female $^{\mathbf{b}}$ & Mean (SD) age $\mathrm{c}^{\mathrm{c}}$ & $\begin{array}{l}\text { Percent } \\
\text { Caucasian }^{d}\end{array}$ & $\begin{array}{l}\text { Mean (SD) } \\
\text { baseline YBOCS }\end{array}$ & $\begin{array}{l}\text { Currently in } \\
\text { OCD treatment }\end{array}$ \\
\hline No coaching $(n=28)$ & $64 \%(n=18)$ & $61 \%(n=17)$ & $35.43(14.27)$ & $89 \%(n=25)$ & $22.82(3.68)$ & $39 \%(n=11)$ \\
\hline Lay coaching $(n=28)$ & $54 \%(n=15)$ & $61 \%(n=17)$ & $40.93(14.09)$ & $89 \%(n=25)$ & $22.71(3.97)$ & $36 \%(n=10)$ \\
\hline Therapist coaching $(n=31)$ & $83 \%(n=26)$ & $68 \%(n=21)$ & $38.65(13.44)$ & $87 \%(n=27)$ & $21.81(4.05)$ & $42 \%(n=13)$ \\
\hline All subjects $(N=87)$ & $68 \%(n=59)$ & $63 \%(n=55)$ & $38.34(13.93)$ & $89 \%(n=77)$ & $22.43(3.89)$ & $39 \%(n=34)$ \\
\hline
\end{tabular}

${ }^{a}$ At least a 2-year college degree; $\chi^{2}(2)=6.424, p=.04$.

${ }^{\mathrm{b}} \mathrm{X}^{2}(2)=0.424, p=.809$.

${ }^{C} F(2)=0.033, p=.967$.

${ }^{d} X^{2}(2)=0.94, p=.954$.

${ }^{\mathrm{e}} F(2)=0.101, p=.904$.

${ }^{\mathrm{f}} X^{2}(2)=0.240, p=.887$. 
enabling patients to track their progress and reinforce their efforts. Step 7 (Continuing Treatment) helps subjects habituate to the next trigger on their list by performing self-exposure sessions. This step may be repeated as many times as necessary, with new triggers being added as subjects habituate to earlier ones and they learn more about planning and doing exposure and ritual prevention in a timely and efficient manner. Step 8 (Troubleshooting) identifies problems in exposure sessions, gives tips to overcome those difficulties, and advises them how to reduce obsessive thoughts (ruminations). It can be accessed repeatedly after Step 7 has been completed at least once. Step 9 (Firming Up Your Gains) helps subjects build on their improvements, reduces relapse risk by teaching them how to anticipate and deal with setbacks, and encourages them to participate in work/social/ leisure activities in the time freed by stopping rituals and obsessions. Each step consists of an introductory video, written text, and various interactive exercises, depending on the purpose of the step. The website also includes simple navigational controls and tools that facilitate selfmanagement of OCD symptoms. Tools include the Trigger Chooser, to identify personal triggers of obsessions and rituals; the Trigger Log, a tool that tracks the user's triggers; and the Exposure Diary, which follows progress through BT Steps. Inclusion of videos (a possible total of 156 dependent on their personalized path through BT Steps), availability via the web rather than by interactive voice response (IVR) telephone plus booklet, and use of specific web tools were major changes from the original IVRbased BT Steps [48].

\section{Assessments}

The BT Steps program administered assessments online at day 1 and then on a regular schedule every 2 weeks thereafter. The assessment battery includes the computeradministered YBOCS $[68,72]$ (the primary outcome), the Work and Social Adjustment Scale [73], and the Depression Scale [74]. Results of these assessments were available to the subject, to permit progress tracking throughout treatment.

In addition, subjects completed two measures of user satisfaction: 1) the System Usability Scale (SUS), a reliable, well-validated 10-item scale which evaluates how 'user friendly' the program was from a technical perspective [75,76] and 2) a 15-item User Satisfaction Scale evaluating the clinical content of online programs on a 4-point scale (strongly agree, agree, disagree, strongly disagree).

Sample size was determined using .80 power to detect a 4-point difference in YBOCS change score, SD of 6.6, a .05 significance level, and planned comparisons using a one tailed $t$-test.

\section{Results \\ Efficacy}

All three treatment arms showed a significant improvement in YBOCS score from baseline to endpoint, with mean changes of $6.5,7.1$, and 6.5 for the no coaching, lay coaching, and therapist coaching arms, respectively (Table 2). These represent effect sizes (Cohens $d$ ) [77,78] of 1.17 (95\% CI 8.62, 4.38), 1.42 (95\% CI 9.37, 4.84), and 1.13 (95\% CI 8.63, 4.34), respectively (all defined as 'large' according to Cohen) [78]. No significant differences in YBOCS change scores between the three treatment arms was observed, $F(2)=0.10, p=.904$. As treatment compliance is a critical factor in treatment outcome, we examined the number of exposure exercises completed by each treatment group. No significant differences were found in the mean number of exposures completed (11.18, 10.1, and 10.8 for no coaching, lay coaching, and therapist coaching groups, respectively, $(F(2)=0.033$, $p=.967)$ ). Similarly, the number of patients in each treatment arm who completed at least one exposure exercise was non-significant $\left(24,24\right.$, and 25 , respectively $\left(\chi^{2}(2)=\right.$ $0.380, p=.827)$ ). As a whole, those subjects who did at least one exposure practice $(n=73)$ did significantly better than those who did not complete any exposure sessions $(n=14)$ (mean (SD) YBOCS change of 7.5 (5.8) vs. 2.5 (4.7), respectively, $t(86)=3.025, p=.003)$.

\section{User satisfaction \\ System usability scale}

The usability of the technical features of the program (i.e., 'user friendliness') was evaluated using the SUS. The mean total score on the SUS was $83.5(\mathrm{SD}=14.9)$ (scale range is $0-100$ with higher score indicating greater usability). This corresponds to a score between 'Good' and 'Excellent' on the SUS (see Table 3).

Table 2 Mean Yale-Brown Obsessive-Compulsive Scale (YBOCS) baseline, endpoint, and change scores by treatment group

\begin{tabular}{|c|c|c|c|c|c|c|}
\hline Treatment arm & Baseline mean (SD) & Endpoint mean (SD) & Change mean (SD) & $95 \%$ confidence interval, change & $t$ & $p$ \\
\hline No coaching $(n=28)$ & $22.82(3.68)$ & $16.32(6.97)$ & $6.50(5.72)$ & $4.29,8.72$ & 6.014 & .000 \\
\hline Lay coaching $(n=28)$ & $22.71(3.97)$ & $15.61(5.88)$ & $7.1071(6.12)$ & $4.73,9.48$ & 6.147 & .000 \\
\hline Therapist coaching $(n=31)$ & $21.81(4.05)$ & $15.32(7.04)$ & $6.4839(6.09)$ & $4.25,8.72$ & 5.930 & .000 \\
\hline
\end{tabular}

$t$ and $p$ are for within subject values. 
Table 3 Results from the user satisfaction questionnaire

\begin{tabular}{|c|c|c|c|c|c|}
\hline Question & $\begin{array}{l}\text { Strongly disagree } \\
(1)(\%)\end{array}$ & $\begin{array}{l}\text { Disagree } \\
(2)(\%)\end{array}$ & $\begin{array}{l}\text { Agree } \\
(3)(\%)\end{array}$ & $\begin{array}{l}\text { Strongly } \\
\text { agree (4) (\%) }\end{array}$ & $\begin{array}{l}\text { Mean } \\
\text { rating }\end{array}$ \\
\hline 1. The objectives of BT Steps were clear & 0 & 0 & 24 & 76 & 3.8 \\
\hline 2. BT Steps was well organized & 0 & 0 & 35 & 65 & 3.7 \\
\hline 3. BT Steps improved my understanding of my OCD & 2 & 7 & 28 & 64 & 3.5 \\
\hline 4. The material in BT Steps was presented in an interesting manner & 0 & 10 & 41 & 48 & 3.4 \\
\hline 5. There were sufficient examples and illustrations in BT Steps & 0 & 9 & 38 & 53 & 3.5 \\
\hline 6. The concepts were clearly presented and easy to understand & 0 & 2 & 28 & 71 & 3.7 \\
\hline 7. The video examples were helpful in illustrating the concepts & 0 & 3 & 42 & 55 & 3.5 \\
\hline 8. The videos with Dr. Greist were helpful in motivating me & 0 & 5 & 41 & 54 & 3.5 \\
\hline 9. The videos featuring OCD sufferers were helpful in guiding me in exposures & 0 & 12 & 29 & 59 & 3.5 \\
\hline 10. I feel capable of applying these techniques I learned in BT Steps & 0 & 7 & 40 & 53 & 3.5 \\
\hline 11. The length of BT Steps was appropriate & 0 & 10 & 50 & 40 & 3.3 \\
\hline $\begin{array}{l}\text { 12. BT Steps was as effective as traditional face to face therapy in helping me with } \\
\text { my OCD }\end{array}$ & 3 & 19 & 42 & 36 & 3.1 \\
\hline 13. I would recommend BT Steps to others & 0 & 0 & 29 & 71 & 3.7 \\
\hline 14. I enjoyed using BT Steps & 0 & 3 & 44 & 53 & 3.5 \\
\hline 15. Overall, I was satisfied with BT Steps & 0 & 2 & 34 & 64 & 3.6 \\
\hline Mean item rating & & & & & 3.5 \\
\hline
\end{tabular}

\section{User satisfaction scale}

Ratings evaluating patient satisfaction with the clinical content of BT Steps are shown in Table 3. Subjects found BT Steps helpful, well organized, and presented in an interesting manner. Ninety-eight percent agreed or strongly agreed with the statement that they were satisfied with BT Steps, and all said they would recommend it to others. Interestingly, when asked which method of therapy (computer vs. clinician) they preferred, $48 \%$ said computer, 33\% traditional face-to-face therapy, and 19\% had no preference, $\chi^{2}(2)=7.48, p=.024$.

\section{User satisfaction with coaching}

Since coaching was a unique variable in the study, we were interested in examining user satisfaction with the coaching component and whether there were any differences in satisfaction between lay coaches and CBT therapist coaches. Descriptive statistics are presented in Table 4. Overall, there was a high level of satisfaction with coaching from both groups, with no significant difference on the mean coaching satisfaction rating between groups $(p=.216)$. We also were interested in whether participants in the coaching conditions felt that coaching was an essential factor in their success. Seventy-three percent 'agreed' or 'strongly agreed' with the statement that they needed coaching to succeed in the program.

\section{Discussion}

In the current study, the addition of coaching did not significantly improve outcomes, using either a lay coach or a CBT therapist coach. This is divergent from other studies that have found coaching beneficial, or even necessary, for positive treatment outcomes [53,58,59]. One possible reason is that while the BT Steps only group did not receive any coaching sessions, they did have an initial orientation call with the project manager. Recent studies have shown that even minimal human contact may be enough to encourage treatment compliance. In his review of the literature ("What Makes Internet

Table 4 Ratings of coaching satisfaction by treatment group

\begin{tabular}{|c|c|c|c|c|}
\hline Question & Lay coach mean (SD) & Therapist coach mean (SD) & $t$ & $p$ \\
\hline 1. Setting goals with my coach helped me stay motivated to work on BT Steps & $3.6(0.58)$ & $3.5(0.71)$ & 0.66 & .511 \\
\hline 2. My coach adequately explained OCD concepts when needed & $3.8(0.38)$ & $3.8(0.67)$ & 0.82 & .935 \\
\hline 3. My coach was available to answer questions outside of coaching calls & $4.0(0.36)$ & $3.8(0.76)$ & 1.10 & .275 \\
\hline 4. My coach provided technical support when needed & $4.0(0.55)$ & $3.6(0.98)$ & 1.51 & .139 \\
\hline Mean item rating & $3.8(0.33)$ & $3.7(0.54)$ & 1.25 & .216 \\
\hline
\end{tabular}

Scale range: 1 = strongly disagree, 2 = disagree, 3 = agree, 4 = strongly agree. 
Therapy Work') [79], Andersson found that the most critical component seemed to be that it includes some form of minimal therapist support, be that email, phone call, or live sessions. Our data seem to bear that out. The pretreatment orientation session may have made it clear to the patient that there was a person behind the support [79]. However a no-treatment control group would be necessary to confirm this hypothesis.

Another possible reason for the absence of benefit of coaching found in several earlier studies of CCBT programs was the difference in program media and components. There was a 20\% greater reduction in YBOCS severity with this web version of BT Steps employing video components including exposure and response prevention vignettes compared with the original IVR version. While readily accessible via telephone, the IVR version also required correlated reading text from booklets. All text in the web version was embedded in the web program at appropriate spots, and the addition of videos and simple navigational tools was an additional difference from the original BT Steps.

Strengths of this study were inclusion of most subjects, excluding only those with significant comorbid depression, suicidal ideation, or severe OCD. The web is steadily more widely available as demonstrated by subject participation from 26 states and two ex-US countries (Canada and Singapore).

Limitations of the study include the sample being mainly college educated (66\% with at least a 2 -year degree, compared to a rate of $28.8 \%$ for all US citizens over 25 years old [80]). While no significant difference was found in our sample between those with and without a college degree (mean YBOCS change of 6.6 vs. 6.5, respectively), only four subjects in our sample had only a high school diploma with no college experience at all. It is unknown if similar results would be found with this cohort. It is also unknown whether similar results would be found in patients with more severe OCD, patients with significant comorbid depression, or patients with limited insight or motivation.

\section{Conclusions}

Results support the use of online self-help for the treatment of moderate to moderately severe OCD. The addition of coaching by either a lay coach or a CBT therapist coach did not significantly improve outcomes. The implications of this finding are important: by reducing the need for live follow-up sessions, treatment becomes both more affordable and more accessible. Reduced demands on therapist's time result in wider dissemination of treatment, since therapists can see more patients, or may see only patients not responsive to unwilling to use CCBT. Under a 'stepped care' model of treatment, matching the appropriate level of intervention, starting with the least restrictive and most effective, enhances treatment outcomes, controls healthcare costs, and helps allocate scare mental health resources more effectively [61-64,81]. Recent studies of stepped care in OCD found equivalent treatment outcomes to standard clinical CBT but significantly lower treatment costs [65-67]. Internetbased CBT fits nicely in the stepped care model, as patients who do not respond to email messages could be stepped up to lay coach follow-up, and from there to traditional CBT therapy, if such therapists are available.

\section{Competing interests}

$K A K, J H G$, and RG have a proprietary interest in the BT Steps computer program. DMJ and HLM declare they have no competing interests.

\section{Authors' contributions}

KAK was the principal investigator and was responsible for developing the study design, conducting of diagnostic interviews, data analysis, and manuscript development. RG helped translate BT Steps from an IVR to a web-based version, coordinated the study, provided lay coaching, and provided input into the study design and manuscript. DMJ and HLM conducted coaching sessions and provided input into the study design. JHG was one of original authors of BT Steps and helped develop the study design, analysis plan, and manuscript. All authors read and approved the final manuscript.

\section{Acknowledgements}

The authors would like to acknowledge the contribution of Dr. Bradley Riemann for the general support and subject recruitment.

\section{Study funding}

This study was supported in part by a grant from the National Institute of Mental Health, National Institutes of Health, and Department of Health and Human Services, under Small Business Innovation Research (SBIR) grant number R43MH090612.

\section{Author details}

${ }^{1}$ Center for Telepsychology, 7601 Ganser Way, Madison, WI 53719, USA. ${ }^{2}$ Waypoint Health Innovations, 137 E. Wilson Street, Suite 812, Madison, WI 53703, USA. ${ }^{3}$ Rogers Memorial Hospital, 34700 Valley Rd, Oconomowoc, WI 53066, USA. ${ }^{4} 255$ S. 17th Street, Suite 1111, Philadelphia, PA 19103, USA. ${ }^{5}$ Healthcare Technology Systems, 6515 Grand Teton Plaza, Suite 100, Madison, WI 53719, USA.

Received: 25 November 2014 Accepted: 4 February 2015

Published online: 22 February 2015

\section{References}

1. Robins LN, Helzer JE, Weissman MM, Orvaschel H, Gruenberg E, Burke JD, et al. Lifetime prevalence of specific psychiatric disorders in three sites. Arch Gen Psychiatr. 1984;41:949-58.

2. Kessler RC, Chiu WT, Demier O, Merikangas KR, Walters EE. Prevalence, severity, and comorbidity of 12-month DSM-IV disorders in the national comorbidity survey replication. Arch Gen Psychiatr. 2005;62(6):617-27.

3. National Advisory Mental Health Council. Health care reform for Americans with severe mental illnesses: report of the National Advisory Mental Health Council. Am J Psychiatry. 1993;150(10):1447-65.

4. Jenike MA. Obsessive-compulsive disorder: efficacy of specific treatments as assessed by controlled trials. Psychopharmacol Bull. 1993;29(4):487-99.

5. Murray CIL, Lopez AD. The global burden of disease: a comprehensive assessment of mortality and disability from diseases, injuries and risk factors in 1990 and projected 2020. Cambridge, MA: Harvard University Press; 1996.

6. DuPont RL, Rice DP, Shiraki S, Rowland CR. Economic costs of obsessivecompulsive disorder. Medical Interface, 1995;102-9

7. Gutierrez CM. Statistical Abstract of the United States U.S. Bureau of the Census, Editor. Blue Ridge Summit, PA: Bernan Associates; 2006.

8. Khanna S, Rajendra PN, Channabasavanna SM. Sociodemographic variables in obsessive compulsive neurosis in India. Int J Soc Psychiatry. 1986;32(3):47-54.

9. Jayakumar C, Jagadheesan K, Verma AN. Disability in obsessive-compulsive disorder: a comparison with schizophrenia. Int J Rehabil Res. 2002;25(2):147-51. 
10. Khan A, Leventhal RM, Khan S, Brown WA. Suicide risk in patients with anxiety disorders: a meta-analysis of the FDA database. J Affect Disord. 2002;68(2-3):183-90

11. American Psychiatric Association. Diagnostic and statistical manual of mental disorders. 5th ed. Arlington, VA: American Psychiatric Association; 2013.

12. Stein DJ, Fineberg NA, Bienvenu OJ, Denys D, Lochner C, Mestadt G, et al. Should OCD be classified as an anxiety disorder in DSM-V? Depress Anxiety. 2010;27(6):495-506.

13. Craig K, Chamberlain S. The neuropsychology of anxiety disorders. In: Stein DJ, Hollander E, Rothbaum BO, editors. Textbook of anxiety disorders. Washington, DC: American Psychiatric Publishing; 2010.

14. Chamberlain SR, Blackwell AD, Fineberg NA, Robbins TW, Sahakian BJ. The neuropsychology of obsessive compulsive disorder: the importance of failures in cognitive and behavioural inhibition as candidate endophenotypic markers. Neurosci Biobehav Rev. 2005;29(3):399-419.

15. Cuthbert BN, Insel TR. Toward the future of psychiatric diagnosis: the seven pillars of RDoC. BMC Med. 2013;11:126.

16. American Psychiatric Association. Practice guideline for the treatment of patients with obsessive-compulsive disorder. Arlington, VA: American Psychiatric Association; 2007.

17. Treatment of obsessive-compulsive disorder. The Expert Consensus Panel for obsessive-compulsive disorder. J Clin Psychiatry. 1997;58 Suppl 4:2-72.

18. National Institute for Health and Clinical Excellence. Obsessive-compulsive disorder: core interventions in the treatment of obsessive-compulsive disorder and body dysmorphic disorder. London: British Psychological Society and Royal College of Psychiatrists; 2005.

19. Baer L, Minichiello WE. Behavioral treatment for obsessive-compulsive disorder. In: Noyes R, Roth M, Burrows GD, editors. Handbook of anxiety. Amsterdam, NY: Elsevier; 1990.

20. Warren R, Thomas JC. Cognitive-behavior therapy of obsessive-compulsive disorder in private practice: an effectiveness study. Anxiety Disorders. 2001;15:277-85.

21. Norton PJ, Price EC. A meta-analytic review of adult cognitive-behavioral treatment outcome across the anxiety disorders. J Nerv Ment Dis. 2007;195(6):521-31.

22. Hofmann SG, Smits JA. Cognitive-behavioral therapy for adult anxiety disorders: a meta-analysis of randomized placebo-controlled trials. J Clin Psychiatry. 2008;69(4):621-32.

23. Abramowitz JS. Variants of exposure and response prevention in the treatment of obsessive-compulsive disorder: a meta-analysis. Behavior Therapy. 1996;27(4):583-600.

24. Kobak KA, Greist JH, Jefferson JW, Katzelnick DJ, Henk HJ. Behavioral versus pharmacological treatments of obsessive compulsive disorder: a meta-analysis. Psychopharmacology (Berl). 1998;136(3):205-16.

25. Foa EB, Liebowitz MR, Kozak MJ, Davies S, Campeas R, Franklin ME, et al. Randomized, placebo-controlled trial of exposure and ritual prevention, clomipramine, and their combination in the treatment of obsessivecompulsive disorder. Am J Psychiatry. 2005;162(1):151-61.

26. Pato MT, Zohar-Kadouch R, Zohar J, Murphy DL. Return of symptoms after discontinuation of clomipramine in patients with obsessive-compulsive disorder. Am J Psychiatr. 1988;145:1521-5.

27. Dunbar G, Steiner M, Bushnell WD, Gergel IP, Wheadon DE. Long-term treatment and prevention of relapse of OCD with paroxetine. Eur Neuropsychopharmacol. 1995;5(3):372.

28. Chambless DL, Hollon SD. Defining empirically supported therapies. J Consult Clin Psychol. 1998;66(1):7-18.

29. Whaley AL, Davis KE. Cultural competence and evidence-based practice in mental health services: a complementary perspective. Am Psychol. 2007;62(6):563-74.

30. Clay RA. Treatment guideline development now under way. Mon Psychol. 2011;42(11):18-9.

31. APA Presidential Task Force on Evidence-Based Medicine. Evidence-based practice in psychology. Am Psychol. 2006;61(4):271-85.

32. Stewart RE, Chambless DL, Baron J. Theoretical and practical barriers to practitioners' willingness to seek training in empirically supported treatments. J Clin Psychol. 2012;68(1):8-23.

33. Stewart RE, Chambless DL. Does psychotherapy research inform treatment decisions in private practice? J Clin Psychol. 2007;63(3):267-81.

34. Torres AR, Prince MJ, Bebbington PE, Bhugra DK, Brugha TS, Farrell M, et al. Treatment seeking by individuals with obsessive-compulsive disorder from the British psychiatric morbidity survey of 2000. Psychiatr Serv. 2007;58(7):977-82.

35. Blanco C, Olfson M, Stein DJ, Simpson HB, Gameroff MJ, Narrow WH. Treatment of obsessive-compulsive disorder by U.S. psychiatrists. J Clin Psychiatry. 2006;67(6):946-51.

36. Patel SR, Simpson HB. Patient preferences for obsessive-compulsive disorder treatment. J Clin Psychiatry. 2010;71(11):1434-9.

37. Hollander E, Wong C. Psychosocial functions and economic costs of obsessive-compulsive disorder. CNS Spectrums. 1998;3(S1):48-58.

38. Fairburn CG, Cooper Z. Therapist competence, therapy quality, and therapist training. Behav Res Ther. 2011;49(6-7):373-8.

39. Andersson G, Carlbring P, Ljotsson B, Hedman E. Guided internet-based CBT for common mental disorders. J Contemp Psychother. 2013;43(4):223-33.

40. Cuijpers P, Donker T, van Straten A, Li J, Andersson G. Is guided self-help as effective as face-to-face psychotherapy for depression and anxiety disorders? A systematic review and meta-analysis of comparative outcome studies. Psychol Med. 2010;40(12):1943-57.

41. Grist R, Cavanagh K. Computerised cognitive behavioural therapy for common mental health disorders, what works, for whom under what circumstances? A systematic review and meta-analysis. J Contemp Psychother. 2013;43(4):243-51.

42. Marks IM, Cavanagh K, Gega L. Hands on help: computer-aided psychotherapy. New York: Psychology Press; 2007.

43. Andersson G, Hesser H, Veilord A, Svedling L, Andersson F, Sleman O, et al. Randomised controlled non-inferiority trial with 3-year follow-up of internetdelivered versus face-to-face group cognitive behavioural therapy for depression. J Affect Disord. 2013;151(3):986-94.

44. Wootton BM, Titov N, Dear BF, Spence J, Andrews G, Johnston L, et al. An Internet administered treatment program for obsessive-compulsive disorder: a feasibility study. J Anxiety Disord. 2011;25(8):1102-7.

45. Marks IM, Baer L, Greist JH, Park JH, Bachofen M, Nakagawa A, et al. Home self-assessment of obsessive-compulsive disorder. $\mathrm{Br} J$ Psychiatr. 1998;172:406-12.

46. Greist JH, Marks IM, Baer L, Kobak KA, Wenzel KW, Hirsch JM, et al. Behavior therapy for obsessive-compulsive disorder guided by a computer or by a clinician compared with relaxation as a control. J Clin Psychiatry. 2002;63(2):138-45.

47. Andersson E, Enander J, Andren P, Hedman E, Ljotsson B, Hursti T, et al. Internet-based cognitive behaviour therapy for obsessive-compulsive disorder: a randomized controlled trial. Psychol Med. 2012;42(10):2193-203.

48. Wootton BM, Dear BF, Johnston L, Terides MD, Titov N. Remote treatment of obsessive-compulsive disorder: a randomized controlled trials. J Obsessive Compuls Relat Disord. 2013;2(4):375-84.

49. Lovell K, Bee P. Optimising treatment resources for OCD: a review of the evidence base for technology-enhanced delivery. J Ment Health. 2011;20(6):525-42.

50. Pozza A, Andersson G, Antonelli P, Dettore D. Computer-delivered cognitive-behavioural treatments for obsessive compulsive disorder: preliminary meta-analysis of randomized and non-randomized effectiveness trials. The Cognitive Behaviour Therapist. 2014;7(e16).

51. Mojtabai R. Unmet need for treatment of major depression in the United States. Psychiatr Serv. 2009;60(3):297-305.

52. Andrews G, Cuijpers P, Craske MG, McEvoy P, Titov N. Computer therapy for the anxiety and depressive disorders is effective, acceptable and practical health care: a meta-analysis. PLoS One. 2010:5(10):e13196.

53. Marks IM, Cavanagh K, Gega L. Computer-aided psychotherapy: revolution or bubble? Br J Psychiatry. 2007:191:471-3.

54. Marks I, Cavanagh K. Computer-aided psychological treatments: evolving issues. Annu Rev Clin Psychol. 2009;5:121-41.

55. Wootton BM, Titov N, Dear BF, Spence J, Kemp A. The acceptability of Internet-based treatment and characteristics of an adult sample with obsessive compulsive disorder: an Internet survey. PLoS One. 2011;6(6):e20548.

56. Kaltenthaler E, Brazier J, De Nigris E, Tumur I, Ferriter M, Beverley C, et al. Computerised cognitive behaviour therapy for depression and anxiety update: a systematic review and economic evaluation. Health Technol Assess. 2006;10(33):iii, xi-xiv, 1-168.

57. McCrone P, Marks IM, Greist JH, Baer L, Kobak KA, Wenzel KW, et al. Cost-effectiveness of computer-aided behaviour therapy for obsessivecompulsive disorder. Psychother Psychosom. 2007;76(4):249-50.

58. Kenwright M, Marks I, Graham C, Franses A, Mataix-Cols D. Brief scheduled phone support from a clinician to enhance computer-aided self-help for 
obsessive-compulsive disorder: randomized controlled trial. J Clin Psychol. 2005;61(12):1499-508.

59. Spek V, Cuijpers P, Nyklicek I, Riper H, Keyzer J, Pop V. Internet-based cognitive behaviour therapy for symptoms of depression and anxiety: a meta-analysis. Psychol Med. 2007;37(3):319-28.

60. National Institute for Health and Clinical Excellence, Guidance on the use of computerised cognitive behavioural therapy for anxiety and depression. London; 2006: National Institute for Clinical Excellence.

61. Franx G, Oud M, de Lange J, Wensing M, Grol R. Implementing a steppedcare approach in primary care: results of a qualitative study. Implement Sci. 2012;7:8.

62. van Straten A, Seekles W, van't Veer-Tazelaar NJ, Beekman AT, Cuijpers P. Stepped care for depression in primary care: what should be offered and how? Med J Aust. 2010;192(11 Suppl):S36-9.

63. NICE. The treatment and management of depression in adults. London: National Institute of Health and Clinical Excellence; 2009.

64. Seekles W, van Straten A, Beekman A, van Marwijk H, Cuijpers P. Stepped care treatment for depression and anxiety in primary care. A randomized controlled trial. Trials. 2011;12:171.

65. Tolin DF, Diefenbach GJ, Gilliam CM. Stepped care versus standard cognitive-behavioral therapy for obsessive-compulsive disorder: a preliminary study of efficacy and costs. Depress Anxiety. 2011;28(4):314-23.

66. Diefenbach GJ, Tolin DF. The cost of illness associated with stepped care for obsessive-compulsive disorder. J Obsessive Compuls Relat Disord. 2013;2(2):144-8.

67. Gilliam CM, Diefenbach GJ, Whiting SE, Tolin DR. Stepped care for obsessive-compulsive disorder: an open trial. Behav Res Ther. 2010:48(11):1144-9.

68. Goodman WK, Price LH, Rasmussen SA, Mazure C, Delgado P, Heninger GR, et al. The Yale-Brown Obsessive Compulsive Scale. II. Validity. Arch Gen Psychiatr. 1989;46:1012-6.

69. Kobak KA, Reynolds WM, Rosenfeld R, Greist JH. Development and validation of a computer-administered version of the Hamilton depression rating scale. Psychol Assess. 1990;2:56-63.

70. Posner K, Brown GK, Stanley B, Brent DA, Yershova KV, Oquendo MA et al. The Columbia-Suicide Severity Rating Scale: initial validity and internal consistency findings from three multisite studies with adolescents and adults. Am J Psychiatry. 2011;168(12):1266-77.

71. First MB, Spitzer RL, Gibbon M, Williams JBW. Structured clinical interview for DSM-IV-TR Axis I disorders, research version, patient edition. (SCID-I/P). New York: Biometrics Research, New York State Psychiatric Institute; 2002.

72. Rosenfeld R, Dar R, Anderson D, Kobak KA, Greist JH. A computer administered version of the Yale-Brown Obsessive Compulsive Scale. Psychol Assess. 1992;4:329-32.

73. Mundt JC, Marks IM, Shear MK, Greist JH. The work and social adjustment scale: a simple measure of impairment in functioning. Br J Psychiatry. 2002;180:461-4.

74. Selmi PM, Klein MH, Greist JH, Sorrell SP, Erdman HP. Computeradministered cognitive-behavioral therapy for depression. Am J Psychiatr. 1990;147(1):51-6.

75. Bangor A, Kortum P, Miller J. Determining what individual SUS scores mean: adding an adjective rating scale. Journal of Usability Studies. 2009:4(3):114-23.

76. Brooke J. SUS: a 'quick and dirty' usability scale, in Usability evaluation in industry. eds. Jordan PW, et al.: Taylor and Francis: London 1996;189-94

77. Cohen J. Effect size index D, in Statistical power analysis of the behavioral sciences. Hillside, NJ: Lawrence Erlbaum and Associates; 1977.

78. Cohen J. Statistical power analysis for the behavioral sciences. 2nd ed. Hillside, N.J: Erlbaum; 1988.

79. Andersson G, Carlbring P, Berger T, Almlov J, Cuijpers P. What makes Internet therapy work? Cogn Behav Ther. 2009;38 Suppl 1:55-60

80. United States Census Bureau. State \& County Quick Facts. January 7, 2015] Available from: quickfacts.census.gov/afd/states/00000.html.

81. Bower P, Gilbody S. Stepped care in psychological therapies: access, effectiveness and efficiency. Narrative literature review. Br J Psychiatry. 2005;186:11-7

\section{Submit your next manuscript to BioMed Central and take full advantage of:}

- Convenient online submission

- Thorough peer review

- No space constraints or color figure charges

- Immediate publication on acceptance

- Inclusion in PubMed, CAS, Scopus and Google Scholar

- Research which is freely available for redistribution 